$\xi=-1$

\title{
SRR loaded half-mode substrate integrated waveguide monopole slot antenna for multiband applications
}

\author{
T V Ramakrishna, B T P Madhav, M Venkateswara Rao, A Babu Rao, A Sunaina, A Avinash, B Shivani \\ Department of ECE, Koneru Lakshmaiah Education Foundation, AP, India \\ *Corresponding author E-mail: btpmadhav@kluniversity.in
}

\begin{abstract}
In this article A two layered printed microstrip line monopole slot antenna is proposed for multiband applications. The proposed antenna comprises of size $47 * 40 * 1 \mathrm{~mm}$ with a modified half mode substrate integrated waveguide (M-HMSIW). By changing the slot width at the bottom ground the multiband characteristics has been obtained. A split ring resonator is placed on beside the patch to enhance the characteristics such as gain and bandwidth of the antenna. The proposed antenna works in the region of LTE band (2.1GHz) and WLAN $(5.7 \mathrm{GHz})$ and it also holds some applications at $\mathrm{x}$-band applications. The simulated return loss and varied parametric vswr of the proposed antenna has been analyzed using ANSYS EM tool. The simulated results state a peak gain of $22 \mathrm{~dB}$ and average gain of $5.7 \mathrm{~dB}$. The result of the proposed antenna states that it is the best suitable for various multiband applications
\end{abstract}

\section{Introduction}

The substrate integrated waveguides have the advantages of low profile and low integrity The applications such as commercial and military applications are mainly comes under the Ultra-wideband (UWB) communication s band which is allocated in the band 3.1 to $10.6 \mathrm{GHz}$. The advantages such as low power consumption (a vital one wireless communication systems and also used to reduces harmful effects in the normal human body), high security for army and military applications, maintain signal quality at low frequency spectrums under the condition of heavy noise in most parts of the body), desirable performance in multipath channels and capability of high signal penetration $[1,2]$. Some of another type of antennas such as broadband frequency dependant as well as independent antennas and also some examples log-periodic antennas, Vivaldi antennas and TEM horns which are meant to be suitable for ultra wideband applications in communication systems Those antennae has a problem for frequency dependant phase centre [1-4]. The UWB monopole printed antenna has a overwhelming advantages such as small size, low profile and low cost. Because of their structure, which also overcome phase centre problem in another antenna [5]. Microstrip antennas are inherently narrow band. Some of the techniques to enhance the bandwidths, are using split ring resonator substrate height [5], less substrate dielectric constant [3], by changing applications in the feeding systems [5], the impedances techniques used for the matching [6], the usage of driven and patristic elements [7], with the use of fractal geometries [5] and using slot antenna which will used for configurations have tremendous applications [4, 7]. Later other types such as, monopole antenna, coplanar wave guide antennas and slot structured antennas used rapidly for the ultra wideband communications, compared to the microstrip antennas these antennas have the lower efficiency [8]. To find the square patch length the basic formulae is $(\lambda / 2 \sqrt{\mathrm{r}})$, where $\lambda$ is known as the free space wavelength, and $r$ is substrate dielectric constant. different techniques have been used for antenna to compact or commonly known as miniaturization [8], since they have some limitations with anyone of the reason such as decrease of sudden change in the impedance bandwidth of the antenna because of the reduction in area of the antenna The antenna size and impedance bandwidth are directly proportional to each other, but they have a complicated relationship. FOR this purpose, the new approach of substrate integrated waveguide leads to a very good solution for all these antenna synthesis problems [10]. The SIW configuration which we have proposed have good hold to the basic antennas [11-19], which are used to clear any gaps in the substrate integrated waveguide and. In this article a half mode substrate integrated waveguide antenna is proposed for multiband characteristics. The proposed antenna and its variations while changing then parameters have been observed. The proposed substrate integrated waveguide antenna and its parameters have been discussed in the subsequent sections.

\section{Design approach of the antenna}

The proposed UWB band notched antenna is designed on HFSS software and Rogers RT Duroid 5880 is taken as the substrate material which is having relative permittivity of 2.2 and this material is used in the both layers. The dimensions of the proposed antenna can be seen in the Table 1 . The width of the microstrip line is $1.52 \mathrm{~mm}$ for $50 \mathrm{ohm}$ impedance. A Wave port is assigned. The upper part of the antenna consists of s semi-circular patch which relates to a feed line and either sides of the feed line split ring resonators is placed to enhance the bandwidth performances. The middle layer that is ground one and ground 2 is connected by the metallic holes which are of dimensions $0.4 \mathrm{~mm}$ and having centre to centre space of $0.8 \mathrm{~mm}$. By the means of a slot which is located at the rear side of the antenna the coupling had its effects through those slots. 


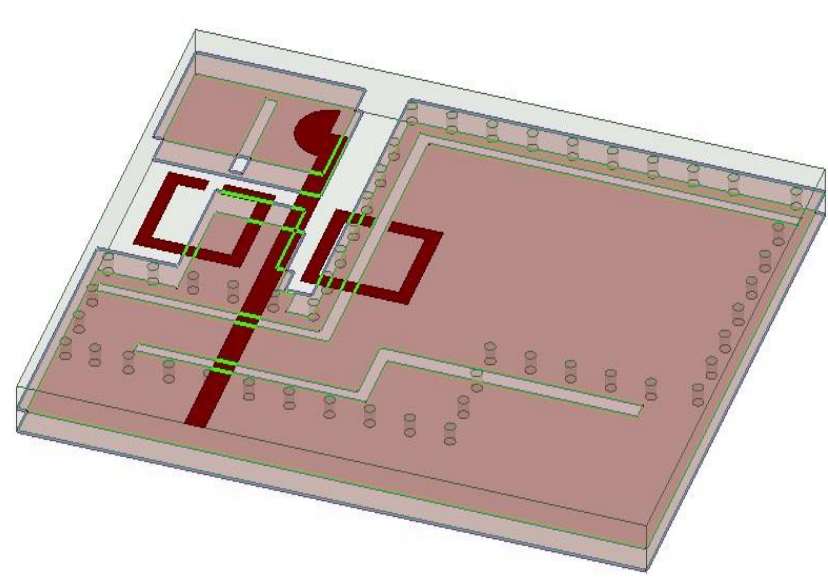

Fig. 1: prospective of the proposed antenna

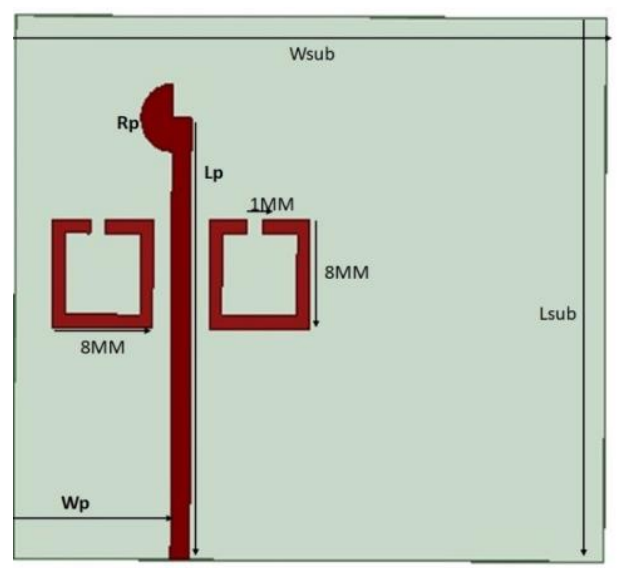

(a) Top patch

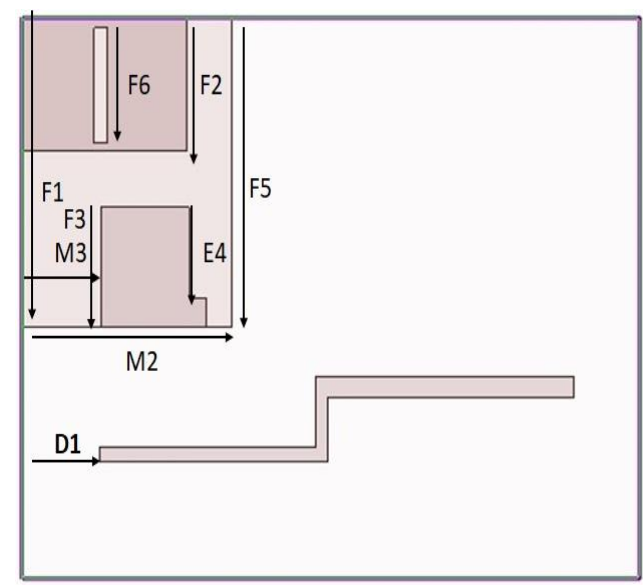

(b) Ground 1

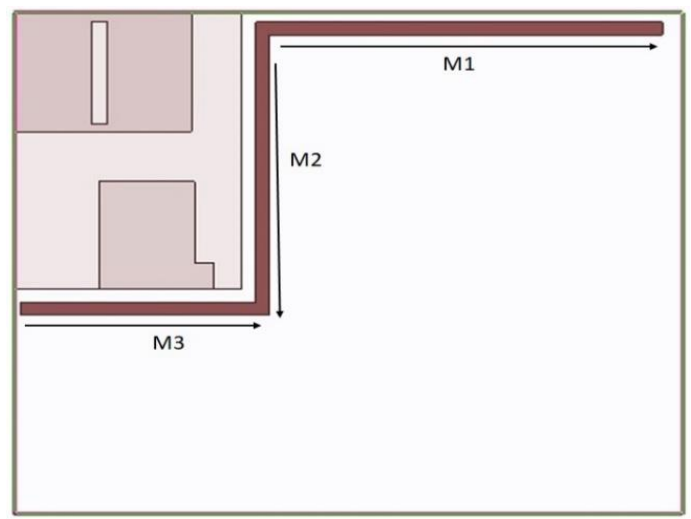

(c) Ground 2

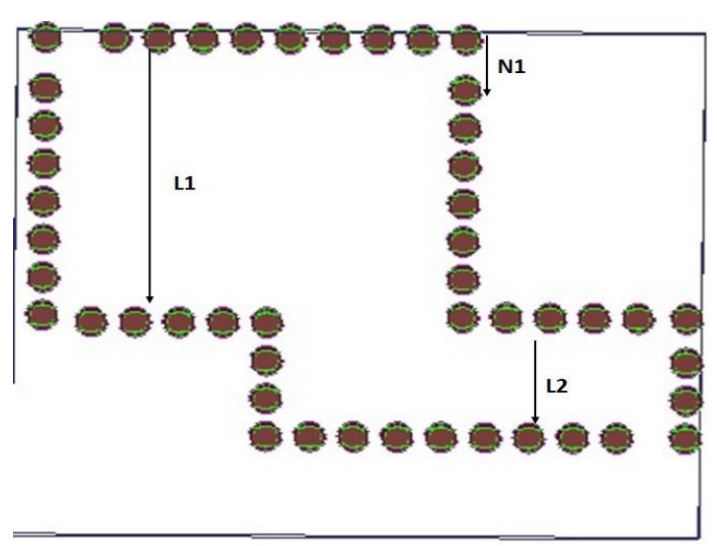

(d) Metallic slots

Table 1:Dimesions of the proposed antenna

\begin{tabular}{lc}
\hline \multicolumn{1}{c}{ Geometrical Entity } & Parametric values(mm) \\
\hline F1/F2/F3/FA4/FA5/FB4/FB5/F6 & $22 / 9.5 / 8.5 / 6.5 / 8.2 / 22 / 28 / 8.2$ \\
LSUB/WSUB/W1/W2 & $40 / 47 / 28.7 / 28.7$ \\
M1/M2/M3/M4/M5/M6 & $16 / 12.5 / 6 / 6.7 / 1.32 / 1$ \\
R1/R2/R3/R4/N1/D1/D2 & $1 / 7.9 / 1.95 / 0.6 / 0.5 / 5.9 / 5$ \\
RP/WP/LP/L1/L2 & $2.5 / 12.5 / 32.5 / 22 / 9.5$ \\
& \\
\hline
\end{tabular}

\section{Results and Discussions:}

The below figure 2 shows the return loss curve of the proposed antenna.it clearly indicates the proposed antenna works in multiband frequencies. Later by changing the parametric the observation on the variations of the antenna can be seen.

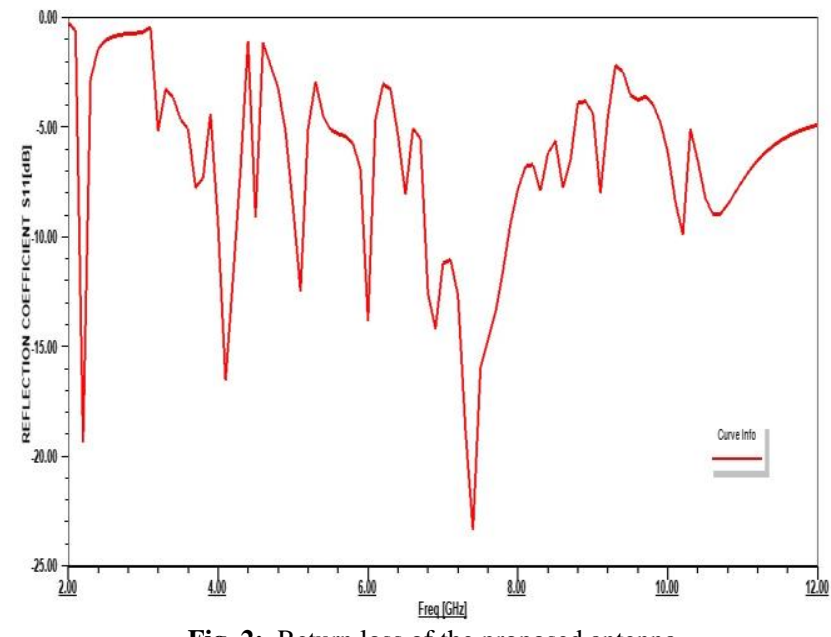

Fig. 2: Return loss of the proposed antenna 


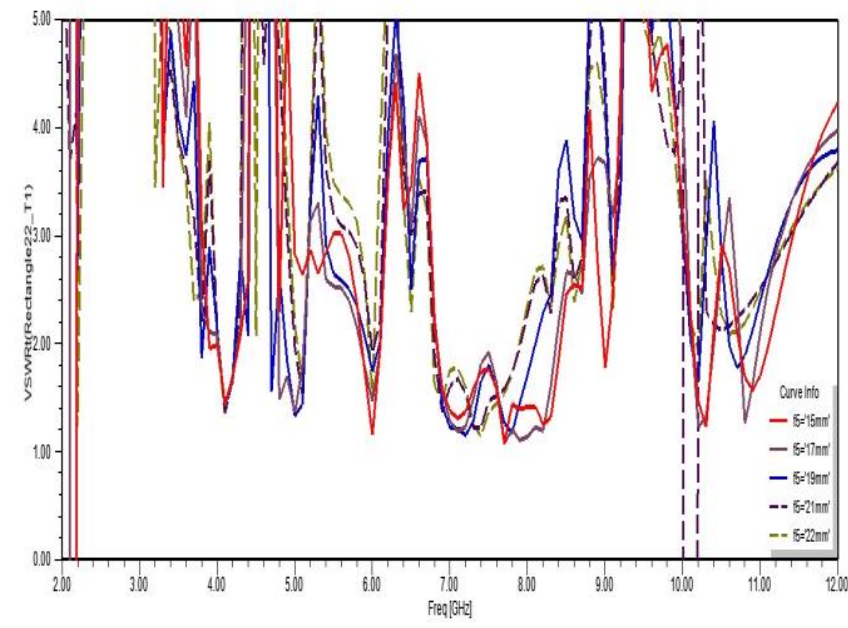

Fig. 3: parametric VSWR study by varying the length L5

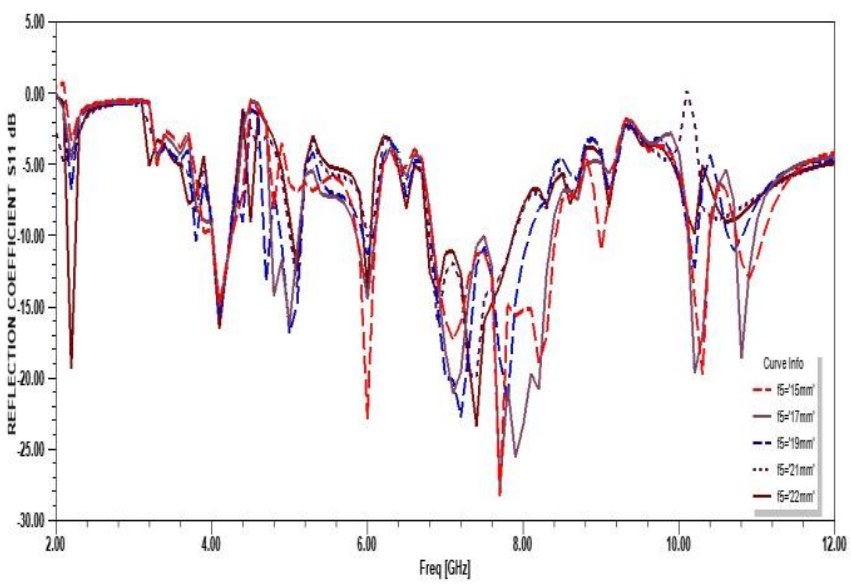

Fig. 4: parametric return loss study by varying the length L5

Figure 3 and figure 4 shows the return loss and vswr variation while varying the slot length F5.By changing length with five variations that is with $15,17,19,21,22$. The antenna depth and resonance has been observed. The figure clearly shows that at $F 5=22$ the antenna is best suitable for the multiband operations

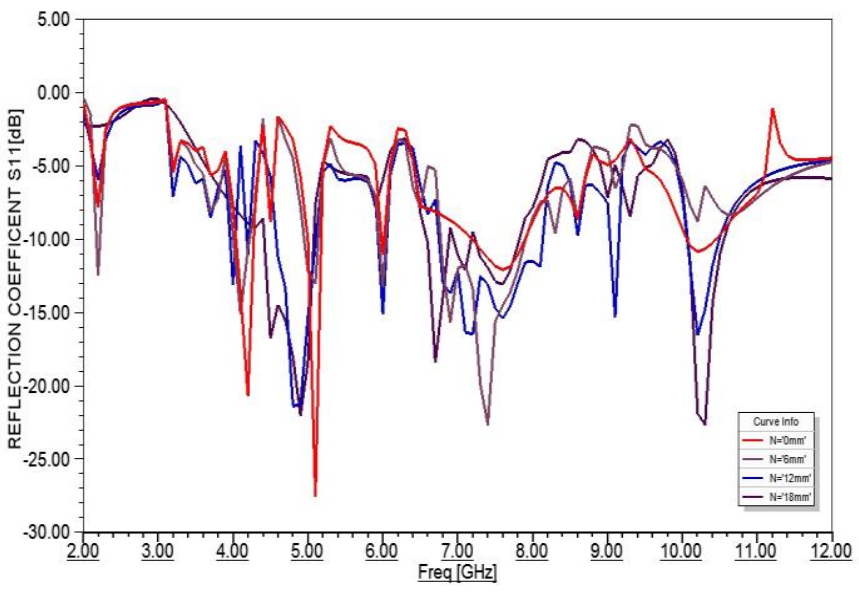

Fig. 5: parametric return loss study by varying the position of the SRR

figure 5 shows the variation by moving the placed split ring resonators along the sides of the feedline it shows by varing the position of the spliring resonator the bandwidth and the change in the bands have been observed

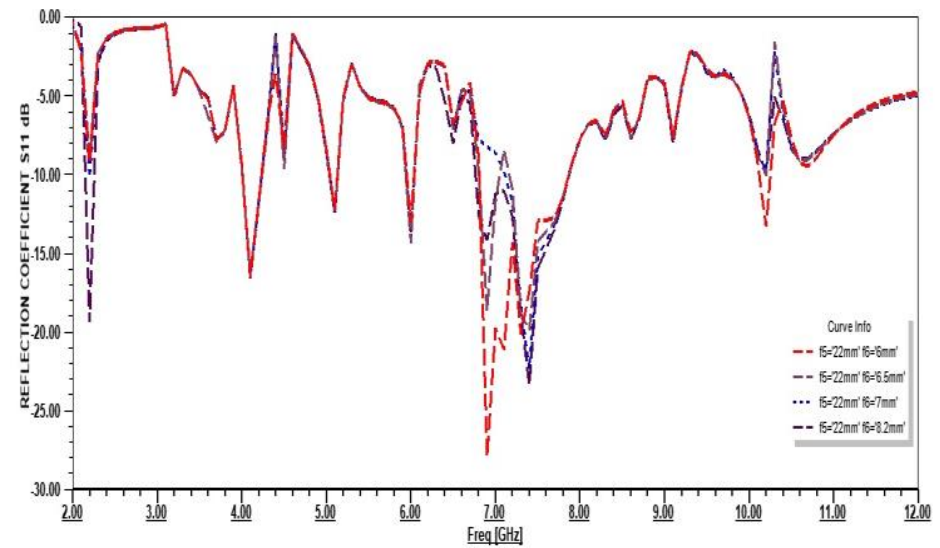

Fig. 6: parametric return loss study by varying the parameter f6

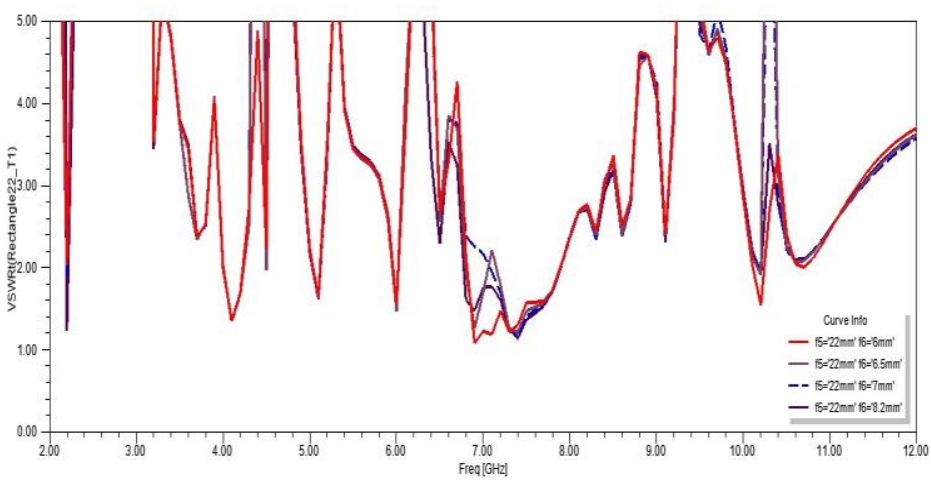

Fig. 7: parametric vswr study by varying the parameter f6

Figure 6 and figure 7 shows the return loss and vswr variation while varying the slot length F6. By changing length with five variations the antenna depth and resonance has been observed. The figure clearly shows that at F6 $=8.2 \mathrm{~mm}$ the antenna is best suitable for the multiband operations. Figure 8 and figure 9 shows the current distributions and e-field of the proposed antenna. In figure 8 the current distribution is take for both notch and working band case where as in figure 9 the E-field distribution is taken for the solution frequency. Figure 11 shoes the gain vs frequency plot of the proposed antenna the peak gain of $22 \mathrm{Db}$ is observed with average gain of $5.2 \mathrm{Db}$
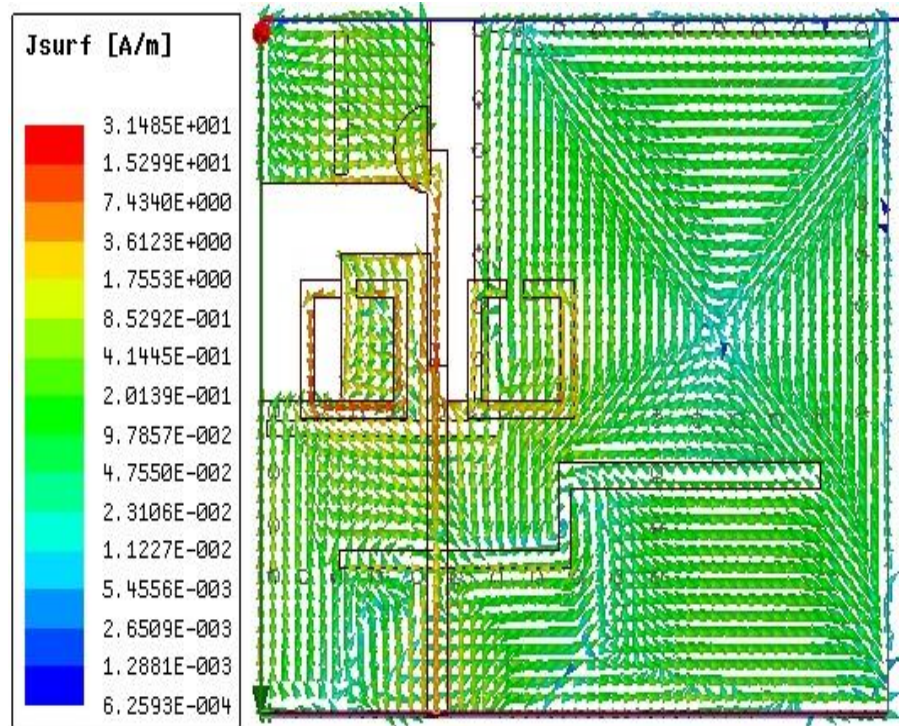


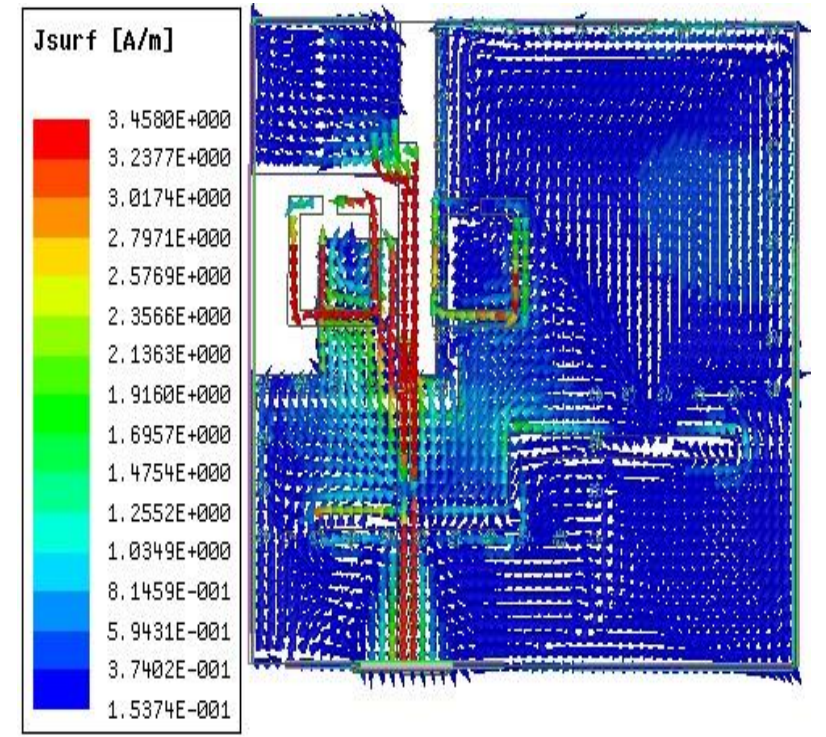

Fig. 8: Current distribution at notch band $(3.1 \mathrm{GHz})$ and working bands $(2.1 \mathrm{GHz})$ of proposed antenna

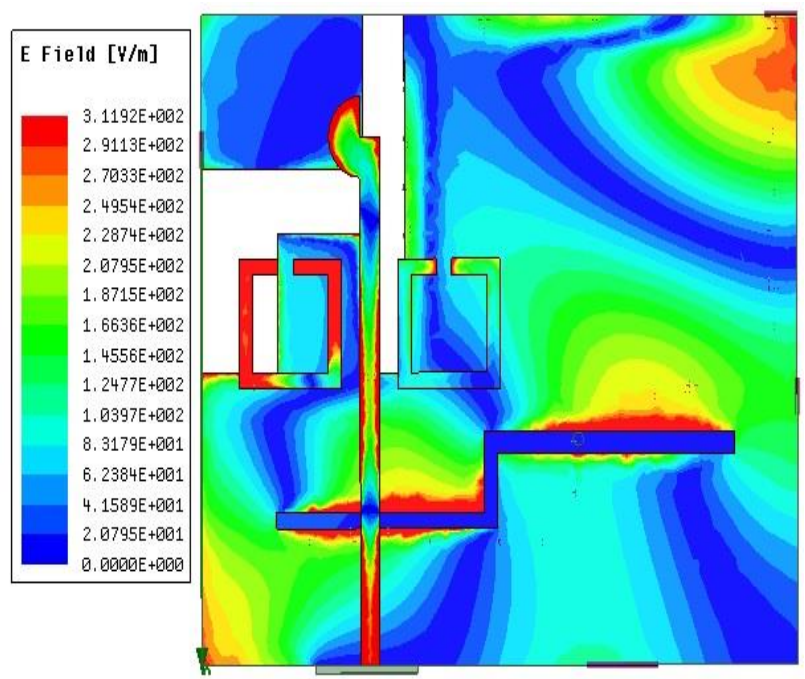

Fig. 9: E-field at solution frequency of the proposed antenna

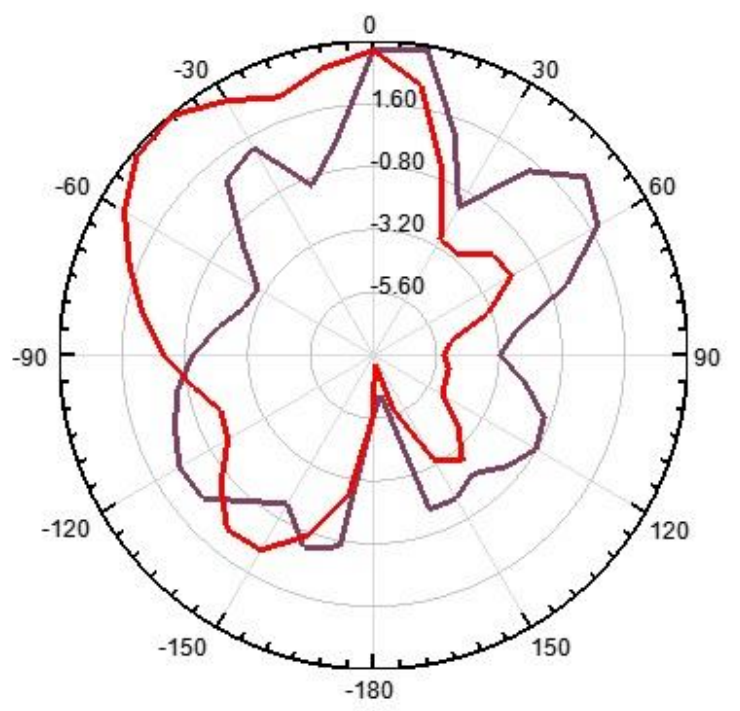

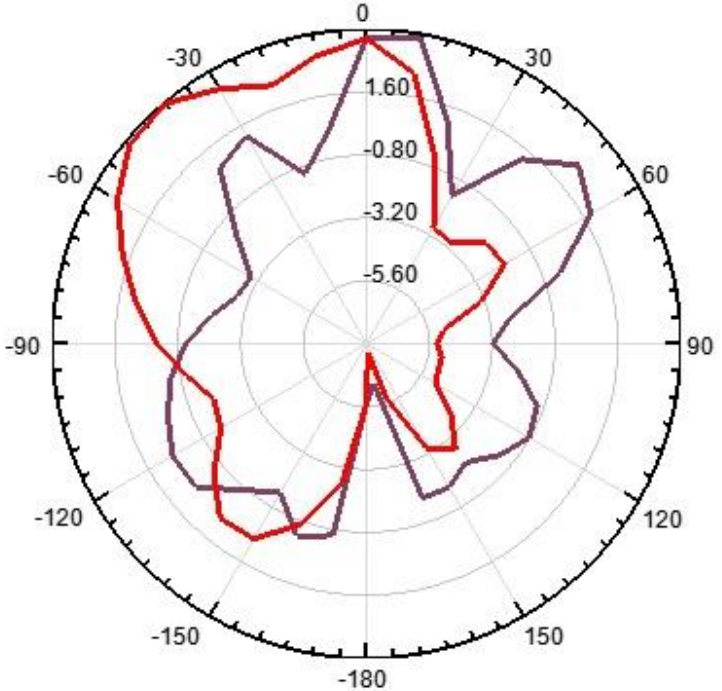

Fig. 10: Radiation patterns at $7.2 \mathrm{GHz}$ and $10.2 \mathrm{GHz}$

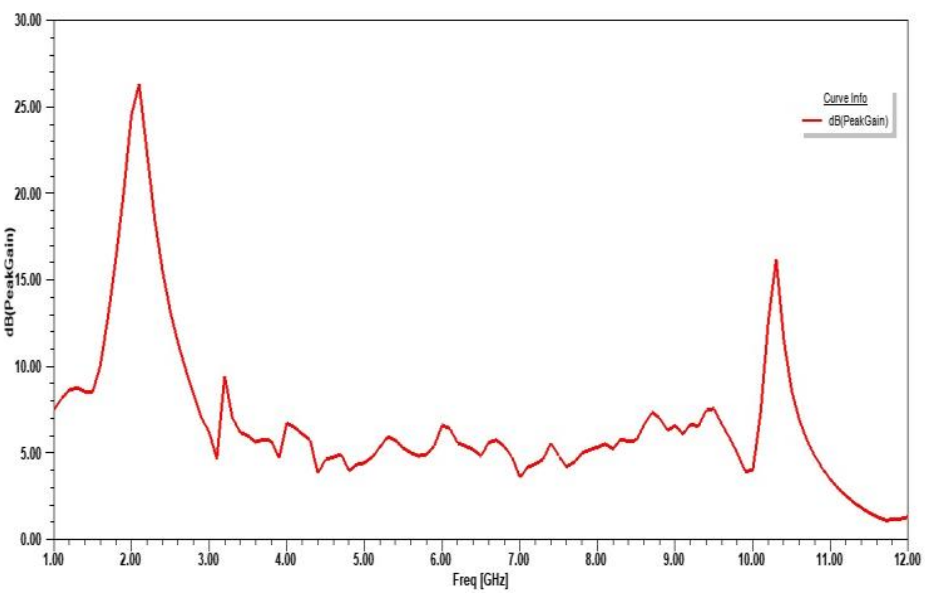

Fig. 11: Gain vs frequency curve of the proposed antenna

\section{Conclusion}

A new multiband half mode substrate integrated waveguide is proposed in this article. The proposed antenna has a high gain of $22 \mathrm{~dB}$ when compared to the normal microstrip antenna. The antenna consists of a split ring resonator at the top most side which is used to enhance the gain and bandwidth of the antenna. The parametric study shows the cavity mode type of analysis and impedance in the proposed antenna. It is observed that The defected ground structure and the slots plays a vital role in changing the operating bands. The antenna has its applications at LTE and WLAN bands.

\section{Acknowledgement}

The authors deeply express their gratitude to ALRC Research Centre, Department of ECE, K L University for their encouragement during this work. Further, we express our gratitude to DST through ECR/2016/000569, FIST SR/FST/ETI-316/2012 and EEQ/2016/000604.

\section{References}

[1] Aiello, G. Roberto, and Gerald D. Rogerson. "Ultra-wideband wireless systems." IEEE microwave magazine 4.2 (2003): 36-47.

[2] Liang, Jianxin, et al. "Study of a printed circular disc monopole antenna for UWB systems." IEEE transactions on antennas and propagation 53.11 (2005): 3500-3504. 
[3] Jilkova, Jana, and Zbyněk Raida. "Ultra-wideband coplanar-fed monopoles: a comparative study." Radioengineering 17.1 (2007): 37.

[4] Cho, Young Jun, et al. "A miniature UWB planar monopole antenna with $5-\mathrm{GHz}$ band-rejection filter and the time-domain characteristics." IEEE transactions on antennas and propagation 54.5 (2006): 1453-1460.

[5] Soltani, S., M. N. Azarmanesh, and P. Lotfi. "Design of small ACS-fed band-notch UWB monopole antenna using particle swarm optimization." Microwave and Optical Technology Letters 52.7 (2010): 1510-1513.

[6] Moghadasi, M. N., et al. "Improved band-notch technique for UWB antenna." IET Microw. Antennas Propag 4.11 (2010): 1886-1891.

[7] Soltani, Saber, et al. "Two novel very small monopole antennas having frequency band notch function using DGS for UWB application." AEU-International Journal of Electronics and Communications 65.1 (2011): 87-94.

[8] Soltani, S., M. N. Azarmanesh, and P. Lotfi. "Design of band notched CPW-fed monopole antenna using two symmetric parasitic elements for UWB applications." Journal of Electromagnetic Waves and Applications 23.11-12 (2009): 1407-1416.

[9] Lotfi, Parisa, Saber Soltani, and Mohammadnaghi Azarmanesh "Triple band-notched UWB CPW and microstrip line fed monopole antenna using broken $\cap$-shaped slot." AEU-International Journal of Electronics and Communications 65.9 (2011): 734741

[10] Mohammadian, N., M-N. Azarmanesh, and S. Soltani. "Compact ultra-wideband slot antenna fed by coplanar waveguide and microstrip line with triple-band-notched frequency function." IET microwaves, antennas \& propagation4.11 (2010): 1811-1817.

[11] Dong, Yuan Dan, et al. "Development of ultrawideband antenna with multiple band-notched characteristics using half mode substrate integrated waveguide cavity technology." IEEE Transactions on Antennas and Propagation 56.9 (2008): 2894-2902.

[12] Zhang, Yan, et al. "Planar ultrawideband antennas with multiple notched bands based on etched slots on the patch and/or split ring resonators on the feed line." IEEE Transactions on Antennas and Propagation 56.9 (2008): 3063-3068.

[13] Li, Wen Tao, Xiao Wei Shi, and Yong Qiang Hei. "Novel planar UWB monopole antenna with triple band-notched characteristics." IEEE Antennas and Wireless Propagation Letters 8 (2009) 1094-1098.

[14] B T P Madhav, T Venkateswara rao, T Anil Kumar, "Design of 4-Element Printed Array Antenna for Ultra-Wideband Applications", International Journal of Microwave and Optical Technology, 13 (2018): 8-17.

[15] B T P Madhav, M Vamsi Krishna Chaitanya Reddy, M Venkateswara Rao, C Mohan Krishna, P Chandan Raj, G Jaya, "Quad Band Filtenna using Split Ring Resonators to Notch Unwanted Frequencies in Medical Application Bands", Journal of Theoretical and Applied Information Technology, 95 (2017): 2070-2077.

[16] B. L. Prakash, B. T. P. Madhav, T. Lokesh, Y. Rajitha Sri, N. V. D. S. Aditya and M. Venkateswara Rao, "Metamaterial Inspired Tri-Band Antenna with SRR and Shorting Stub", ARPN Journal of Engineering and Applied Sciences, 12 (2017): 6197-6205.

[17] B. T. P. Madhav, D. Naga Vaishnavi, G. Vanaja, G. Jayasree and S. Mounika, "Design and analysis of metamaterial antenna with EBG loading", Far East Journal of Electronics and Communications, 14 (2015): 127-136.

[18] M Ajay babu, B T P Madhav, D Naga Vaishnavi, P Radhakrishna, N Bharath, K Madhuri, K Bhavani Prasad, K Harish, "Flared V-Shape Slotted Monopole Multiband Antenna with Metamaterial Loading", International Journal of communications Antenna propagation, 5 (2015): 93-97.

[19] B. T. P. Madhav, M. Manjeera, M. S. Navya, D. Sharada Devi, V. Sumanth, Novel Metamaterial Loaded Multiband Patch Antenna, Indian Journal of Science and Technology, ISSN 0974-6846, 9 (2016): pp 1-9. 